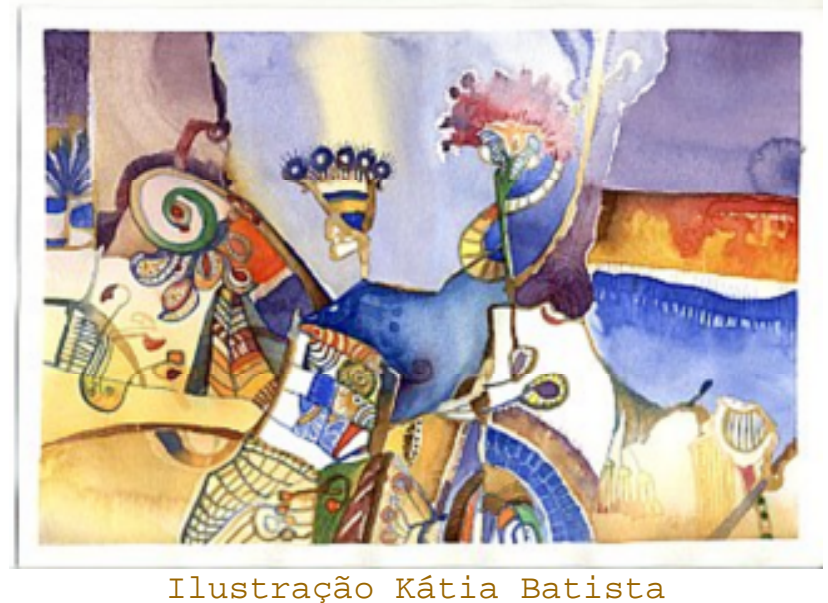

\title{
Recepção crítica e análise de textos literários
}

\section{Penha Lucilda de Souza Silvestre}

Penha Lucilda de Souza Silvestre é mestre em Letras pela Universidade Estadual de Maringá-PR.

\section{Resumo}

Este trabalho tem como objetivo a leitura crítica de Um homem no sótão e Uma velhinha de óculos, chinelos e vestido azul de bolinhas brancas, de Ricardo Azevedo. Dentre as várias possibilidades de análise de uma obra literária, optamos por abordar elementos estruturais da narrativa, bem como tópicos associados à especificidade do gênero e aspectos relacionados à construção lingüística dos textos em pauta. Desse modo, procuramos não só considerar a organização estrutural das narrativas, mas também o efeito da leitura do texto literário, na concepção de Wolfgang Iser e sua recepção propriamente dita, sob a ótica de Hans Robert Jauss.

Palavras-chave: Literatura, literatura infanto-juvenil, Ricardo Azevedo. 


\section{Considerações Iniciais}

A Literatura, o discurso poético e ficcional, quando respeitadas suas características, entre as quais, ressalto mais uma vez, incluo a possibilidade de poder abordar o contraditório, permite a identificação emocional entre a pessoa que lê o texto e, assim, pode representar, dentro ou fora da escola, um preciso espaço para que especulações vitais - feitas pelo leitor, seja consigo mesmo, seja com outras pessoas - possam florescer.

Azevedo

No que diz respeito às literaturas infantil e juvenil contemporâneas brasileiras, percebemos a intensa multiplicação de autores e de obras que despontam no mercado livreiro. Todavia, verificamos lacunas nos estudos dessa vertente. Dentre elas, observamos a carência de pesquisas que abordem a produção e a recepção de textos literários voltados para essa faixa de público-leitor, especialmente, para a produção de Ricardo Azevedo. Partindo desses pressupostos, este estudo tem por objetivo a análise e a recepção crítica dos textos Um homem no sótão e Uma velhinha de óculos, chinelos e vestido azul de bolinhas brancas (1994), de Azevedo (1). Dentre as várias possibilidades de analisar uma obra literária, optamos por abordar os aspectos estruturais da narrativa: tópicos associados às especificidades do gênero, especialmente, narrador, focalização e personagens, como também aspectos relacionados à construção lingüística dos textos em questão, com o intuito de situarmos essas obras no cenário da literatura infanto-juvenil brasileira nas últimas décadas. Realizamos uma crítica integradora com o intuito de observar se as obras apresentam um caráter emancipador decorrente de sua organização ficcional e se asseguram a interação do leitor com o texto.

\section{Recontando histórias}

Um homem no sótão (2) narra a história de um autor de contos para crianças que morava num sótão, na rua da Consolação, e que, raras vezes, saía de casa. Um dia, tentando escrever a história "Aventuras de três patinhos na floresta", inesperadamente, aparece uma raposa muito nervosa, inconformada com o rumo da história, reclamando de sua eterna vilania. Afinal, era carnívora, o que justificava a sua atitude: comer os patinhos da história. Estes, por sua vez, também saem da cabeça do autor e o alertam de que sempre caçaram minhocas, peixes e besouros. Em seguida, numa noite de lua cheia, depois que o escritor se recuperara do susto, teve a idéia de escrever "A linda princesa do castelo". E assim, sucessivamente, outros personagens saem de sua cabeça e contestam suas histórias como o sapo, a princesa, os anõezinhos e a bruxa. 
O autor de contos procurou um médico, tirou férias e, ao retornar, começou a escrever uma história bem diferente, mas a confusão repetiu-se. O escritor adoeceu, trancou-se dentro de casa e deixou de viver. Passado um longo tempo, ao ver um passarinho ciscando em cima do armário, perguntou qual era a história, abriu a janela, espantou a passarada e percebeu que a vida continuava. Então, retornam a vida e a vontade de escrever história de gente como ele, escrever coisas de seu tempo. Finalmente, começa a escrever Um homem no sótão.

o texto é organizado em cinco capítulos numerados e não titulados e, na abertura de cada um, há uma vinheta representativa. A estrutura da obra, aparentemente, é linear. Mas essa linearidade é relativizada pelas diversas histórias encaixadas e caracteriza-se pela metaficção. A página de abertura do texto, por exemplo, corresponde ao número cinqüenta e sete e a última, ao número um. O final da história é aberto.

Em Um homem no sótão, a criação narrativa fala sobre si mesma. o escritor personagem revela ao leitor o processo de inventar histórias. Nessa obra, a metaficção é uma das características predominantes: "Era uma vez um autor de contos para crianças que passava o tempo inteirinho, inclusive sábados, domingos e feriados, escrevendo histórias para crianças."(3) No decorrer da narrativa, o narrador relata o fazer literário. Além desse aspecto, o texto trata também da angústia espiritual, das impressões emocionais e sentimentais, dos conflitos interiores e, com veemência, relativiza pontos de vista.

Uma velhinha de óculos, chinelos e vestido azul de bolinhas brancas (4) conta a história de seis amigos que estão sentados na calçada, no final da tarde, quando surge do outro lado da rua, no portão de uma casa, uma velhinha de óculos, chinelos e vestido azul de bolinhas brancas. Não a conhecem e cada um imagina quem ela poderia ser. Um dos meninos diz que ela é uma escritora de histórias infantis, imagina "um montão de aventuras, contos de fadas, reis, gigantes, amores e piratas, que acabaram virando livros". Outro diz que é uma feiticeira que lê livros de magia e tem objetos variados para fazer feitiços e seu companheiro, provavelmente, é um vampiro. Em seguida, outro comenta que a velhinha sempre foi uma dona de casa, casada há anos com um velhinho de nariz torto. Para outro, a velhinha é professora de ginástica e "deve ser formada e diplomada em educação física", casada com um atleta. Outro menino diz que a velhinha é viúva e solitária. Outra opinião sugere que a velhinha é artista de teatro dessas "que sobem no palco e se transformam completamente".

A narrativa apresenta várias histórias dentro de uma história maior, enfocando e desdobrando as várias possibilidades e 
hipóteses de construção da identidade da velhinha. As opiniões veiculadas pelos meninos desfilam sucessivamente num espaço comum, no qual narram e descrevem fatos passados e presentes da vida da velhinha. A independência dos episódios imaginados por eles reforça a arquitetura fragmentária da obra, pois não existe uma transição entre as sugestões enunciadas. Conforme Faria, no texto intitulado "A questão da literatura infantojuvenil": "o autor não nos dá uma história propriamente dita, mas estimula o leitor a apreciar várias histórias a partir de um único ponto e por fim dar a sua versão" (5). A história está organizada em dois planos: no primeiro, a reunião de um grupo de amigos que estão conversando, sentados na calçada. Em outro plano, a criação de diversas histórias imaginadas pelos meninos.

Uma velhinha de óculos, chinelos e vestido azul de bolinhas brancas aborda a questão da identidade e os diferentes pontos de vista. E a partir da construção imaginada pelos personagens outros temas se destacam, como: a invenção de histórias, a música, a saudade, a imaginação, a fantasia, a rotina, a dança, a relação familiar, a relatividade das coisas.

\section{Especificidades do gênero em Um homem no sótão e Uma velhinha de óculos, chinelos e vestido azul de bolinhas brancas, de Ricardo Azevedo}

O narrador, considerado um personagem do texto, cumpre uma função particular no processo narrativo, pois organiza o discurso, conduz a estruturação e a sucessão de fatos do mundo ficcional, além de ser responsável pela focalização que se instala na história narrada. Nos textos de Azevedo, de forma geral, podemos reconhecer algumas categorias peculiares, pois se estabelece uma construção híbrida dos narradores: heterodiegéticos, homodiegéticos e autodiegéticos. Assim, há uma multiplicação de vozes que permite a participação do leitor no mundo ficcional, de modo que o texto não se converte num manual de regras para a percepção da realidade circundante.

O narrador de Uma velhinha de óculos, chinelos e vestido azul de bolinhas brancas usa a $3 a$ pessoa do discurso para narrar. Ele demonstra ter conhecimento da história, introduz e estrutura o texto discursivo, não participa do conflito dramático, mas atua como mediador no ato de produção da narrativa, definindo-se como heterodiegético, isto é, a voz narrativa está fora dos eventos que narra:

Seis amigos estão sentados na calçada. A tarde vai chegando ao fim. No portão de uma casa, do outro lado da rua, aparece uma velhinha de óculos, chinelos e vestido azul de bolinhas brancas. 
Os amigos começam a conversar. Cada um diz o que pensa. Surgem seis opiniões diferentes a respeito da mesma vizinha.

Em seguida, cada opinião é apresentada uma após a outra, sem interrupção ou alguma observação do narrador, que se afasta da história, cedendo lugar aos meninos, dando-lhes a voz, portanto, privilegiando o falar das crianças. Desse modo, dispensa o restante da narrativa para que elas relatem e expressem suas suposições, alterando a posição da focalização da narrativa. Essa mudança de perspectiva não é prejudicial, ao contrário, provoca a multiplicidade e a potencialização de interpretações. Por conseguinte, cada amigo conta, ou melhor, cria a imagem da velhinha a partir de seus respectivos pontos de vista: uma escritora, uma feiticeira disfarçada, uma dona de casa, uma professora de ginástica, uma viúva ou uma artista de teatro.

Como percebemos, as seis opiniões apresentam, inicialmente, a locução pra mim e, em seguida, as imaginações são relatadas sob a ótica de cada um dos garotos, revelando suas suposições, permitindo possíveis construções da imagem da velhinha, totalmente diversas. Desse modo, há uma mudança na focalização: Pra mim, ou seja, o texto passa a ser narrado em primeira pessoa. De acordo com Iser: "Cada perspectiva não apenas permite uma determinada visão do objeto intencionado, como também possibilita a visão das outras".(6)

As seis opiniões articuladas organizam um quadro variado e as diversas perspectivas marcam um ponto em comum. Todavia, a identidade, tanto dos meninos como da velhinha, não é dada explicitamente, mas imaginada. Ela se atualiza, portanto, nos "atos da imaginação" do leitor. Segundo Iser, "é nesse ponto que o papel do leitor, delineado só na estrutura do texto, ganha seu caráter efetivo" (7). Assim, reconhecemos a função emancipatória do texto literário, pois estabelece uma situação comunicativa com o leitor infantil, instigando-o a realizar outras construções da imagem da velhinha.

- narrador de Um homem no sótão usa a $3 a$ pessoa do discurso para narrar. Ele demonstra ter conhecimento de toda a história. Embora não participe do conflito dramático nem da história narrada, apresenta voz tão próxima às vozes do interior da narrativa que, muitas vezes, parece que vive o episódio com elas. Desse modo, considerando o papel essencial que tem na obra literária, o narrador estrutura o texto discursivo e atua como mediador no ato de produção da narrativa, definindo-se como heterodiegético, Está fora da história que conta, mas conhece tudo sobre o personagem protagonista e sobre os secundários, portanto é onisciente e coloca-se numa posição de transcendência: "Foi numa sextafeira, mês de agosto. Fazia um frio de rachar. O autor passara 
a noite tentando inventar uma história nova, e nada! Estava sem um pingo de inspiração" (8).

Nesse sentido, a focalização onisciente, denominada focalização zero (narrativa não focalizada), corresponde à visão do narrador onisciente que faz uso de sua capacidade de conhecimento praticamente ilimitada. Por meio do discurso direto e do indireto-livre, o narrador faz com que as cenas sejam focalizadas sob a ótica dos personagens. Às vezes, a voz do narrador se confunde com a do personagem protagonista, estabelecendo-se, assim, estreita sintonia com a estrutura fragmentária do romance: "Sentado em sua poltrona enorme, passava horas pensando e meditando. Lembrava dos patinhos, da raposa, da discussão em que se metera, dos patinhos defendendo logo quem e da raposa fazendo o que fez" (9).

Os ângulos de visão parcial vão se justapondo ao longo da história através do narrador, que ora parece assumir o ponto de vista do personagem, manifestando-se como intruso, registrando posições ideológicas, ora abre espaço para o escritor de contos. Assim, vão se acumulando flagrantes, aparentemente desconexos que registram o cotidiano dramático do escritor em plena atuação na construção de uma obra literária: "Lá dentro, no fundo, profundo do coração, continuava cheio de dúvidas. [...] Não conseguia se conformar com o sapo virando príncipe desencantado" (10).

O narrador deixa a impressão de que dialoga com o escritor como se fosse a sua consciência. Um exemplo dessa situação acontece quando o escritor vai ao médico devido às perturbações provocadas pelos personagens que saíam de sua cabeça:

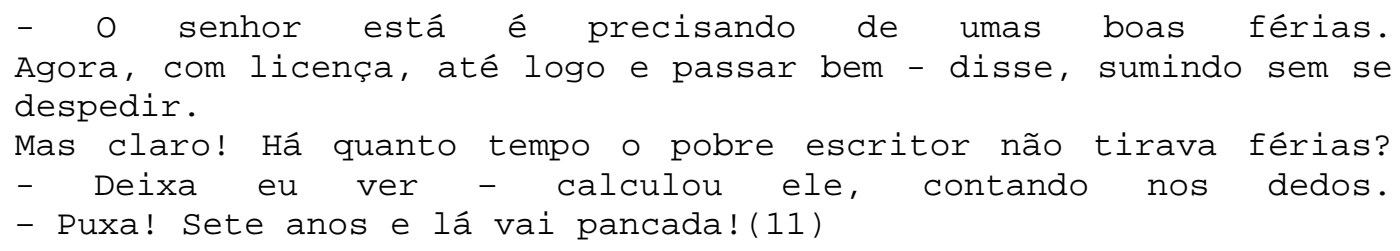

Os discursos diretos são seguidos por verbos dicendi e anunciam mudança de nível discursivo. Também são assinalados por indicadores grafêmicos adequados: o uso de dois pontos e travessão. Todavia, há ocorrências que provocam o afastamento da forma convencional. Isso ocorre quando se trata do personagem protagonista, como assinalamos em alguns casos dos textos do escritor.

Há várias ocorrências do discurso direto, no qual os personagens manifestam 0 seu ponto de vista em relação aos fatos que os circundam. Além desse recurso, percebemos a aproximação do monólogo interior, uma das técnicas utilizadas 
pelos escritores contemporâneos, a fim de representar implicações psicológicas dos personagens. Além de descrever o tempo interior, que também é uma estratégia de relato de fala:

Ia fazer uma história diferente de tudo o que fizera antes. As personagens seriam uma bruxa e alguns anões, mas, aí estava a grande diferença: tanto a bruxa como os anõezinhos iam se dar bem, ser amigos e viver às mil maravilhas. Seu plano, em resumo, era escrever uma história sem bandidos nem mocinhos. "Chega de confusão!", pensou o escritor com um brilho esperto nos olhos(12).

Se não fosse a presença do pronome possessivo "seu" na $3 a$ pessoa, em vez de "meu", seria um monólogo. O narrador e o personagem se fundem numa espécie de interlocutor híbrido, então, a presença do discurso indireto livre: "Vestiu a camisa, penteou o cabelo, passou perfume, saiu, mas, quando chegou na praia... cadê a moça bonita? Tinha ido embora. Que azar!" (13). Ou então: "Escreveu, escreveu, escreveu, durante longo tempo, sem ser incomodado. Que bom fazer aquilo que a gente gosta sem ninguém para atrapalhar!" (14).

Gisèle Valency, no texto intitulado "A crítica", diz que o discurso indireto livre "faz ouvir, na voz do narrador, os ecos de outra voz. Porém, mesmo quando elas estão separadas, o discurso parece a um só tempo narrado e citado" (15). Há uma mistura de vozes, resultado de uma associação do discurso direto e do discurso indireto, os quais permitem ao leitor visualizar as condições intrínsecas do personagem. Isso porque - narrador não utiliza apenas a sua voz como canal de informação, mas abre espaço para outras vozes, especialmente, das histórias encaixadas.

Nesse sentido, observamos a importância de desvelar os elementos constitutivos das narrativas, pois são como fios que se entrecruzam e geram sentidos. Em outras palavras, eles não podem ser dissociados, pois um complementa o outro. Segundo Iser, o texto narrativo apresenta algumas perspectivas importantes, como a do narrador, dos personagens, do enredo e do leitor ficcional. Constatamos que, nos textos de Azevedo, esses pontos perspectivísticos se entrelaçam e oferecem, através dos pontos de vista presentes neles, a elaboração de diferentes visões. O texto Uma velhinha de óculos, chinelos e vestido azul de bolinhas brancas apresenta uma série de perspectivas como a do narrador observador e dos personagens que protagonizam a velhinha. Essas perspectivas se entrelaçam e cabe ao leitor a atualização da história a partir de sua imaginação. 


\section{Em síntese}

Jauss comenta que a compreensão estética leva o leitor a uma mudança de expectativas em relação a si mesmo e ao mundo que o cerca. Tanto para Iser como para Jauss, o leitor é o elemento responsável pelo ato da leitura, porque ativa e alarga os significados do texto. Se há um alargamento de expectativa, por conseguinte, há a emancipação do leitor. De acordo com Iser, a Estética da Recepção:

sempre lida com leitores reais, concretos, por assim dizer, leitores cujas reações testemunham experiências historicamente condicionadas das obras literárias. Uma teoria do efeito estético se funda no texto, ao passo que uma estética da recepção é derivada de uma história dos juízos de leitores reais (16).

O leitor proposto por Jauss é real, mas vale assinalar que a recepção do texto literário não é uniforme para toda leitura realizada por diferentes receptores. O resultado da interação entre o texto e o leitor depende da experiência de leituras prévias, do conhecimento de tipologias textuais e de estratégias de leitura. Por conseguinte, ao fazermos o levantamento de indeterminações e lacunas presentes no texto literário de Azevedo, devemos questionar até que ponto o leitor real faz as associações que o texto suscita.

O leitor dos textos de Azevedo assegura o seu lugar no mundo ficcional criado pelo escritor, pois sua participação ocorre naturalmente em decorrência da organização estrutural, porque há lacunas que instigam a sua presença na formulação de sentidos da história relatada. Temos a impressão que Azevedo constrói um projeto definido de organização dos elementos estruturais e temáticos, uma vez que seus textos apresentam características similares. No caso da construção do narrador e da focalização, percebemos uma desconstrução das normas tradicionais. Isto é, há uma multiplicidade de vozes no interior da narrativa.

Assim, desfilam nos textos do escritor narradores que podem exercer influência, maior ou menor, na atuação dos personagens e do leitor. Há narradores que omitem informações, examinam reações dos personagens, identificam-se com a visão do protagonista ou opõem-se a eles, compartilham com o espectador ou relatam fatos de forma que o espectador teça uma interpretação própria, sem a intervenção dos comentários do narrador. Esse processo de organização da narrativa, peculiar em Ricardo Azevedo, desfaz a perspectiva unívoca do texto e resulta numa construção plurissignificativa. 


\begin{abstract}
Critical Reception and reading text analysis: the narrator's construction in "Um homem no sótão e Uma velhinha de óculos, chinelos e vestido azul de bolinhas brancas, by Ricardo Azevedo. This work has as goal the critical reading of Um homem no sótão and Uma velhinha de óculos, chinelos e vestido azul de bolinhas brancas, by Ricardo Azevedo. Among several possibilities of readings of a literary work, we chose to study the structural elements of the narrative, such as topics associated to the specification of gender as aspects related to the linguistic construction of these texts.
\end{abstract}

Key-words: literature, literary work, Ricardo Azevedo.

\title{
Notas
}

(1) Ricardo Azevedo (São Paulo - 1949 - ) formou-se Bacharel em Comunicação Visual na Faculdade de Artes Plásticas da FAAP em 1975, em São Paulo. Escritor e ilustrador, Mestre em Letras pela Universidade de São Paulo e doutorando em Teoria Literária. Começou a produzir livros infantis em 1980, com O peixe que podia cantar. Em 1983, com o livro Um homem no sótão, obteve menção honrosa na Bienal de Ilustrações de Bratislava (República Tcheca). Azevedo conquistou, em 1989 e 1991, prêmios Jabuti de Melhor Livro Infantil pelos livros Alguma coisa e Maria Gomes. Em 1995, recebeu o prêmio de melhor livro juvenil para Pobre corinthiano careca, concedido pela Associação Paulista de Críticos de Arte. Também nesse ano participou da Mostra de Ilustradores Brasileiros de Bolonha, ano em que o Brasil foi o país homenageado daquela que é a maior Feira internacional do mercado editorial de livros para crianças. Sua obra poética inclui Estão batendo na porta (1986), Brincando de adivinhar (1996), Dezenove poemas desengonçados (1998), Meu material escolar (2000), dentre outros livros. Alguns livros foram traduzidos na Alemanha, em Portugal, no México e na Holanda. Em 1998, obteve simultaneamente dois prêmios Jabuti, que é o prêmio nacional de maior prestígio: de Melhor Livro Infantil para o livro Dezenove poemas desengonçados (Ática) e de Melhor Livro Juvenil para A outra enciclopédia canina (Companhia das Letrinhas). Em 2004, recebe o prêmio Jabuti da categoria infanto-juvenil para o texto Contos de enganar a morte. Até o ano de 2003, o autor publicou mais de oitenta títulos, com destaque para a literatura popular.

(2) AZEVEDO, R. Um homem no sótão. Ilustrações Ricardo Azevedo. São Paulo: Cia Melhoramentos, 1982. 30p. Para a leitura de nosso trabalho utilizamos a versão republicada pela editora Ática (2001).

(3) AZEVEDO, 2004, p. 57.

(4) AZEVEDo, R. Uma velhinha de óculos, chinelos e vestido azul de bolinhas brancas. Ilustrações Ricardo Azevedo. São Paulo: Companhia das Letrinhas, 1998.

(5) FARIA, 1999, p. 99.

(6) ISER, 1996, p. 179.

(7) ISER, 1999, p. 75.

(8) AZEVEDO, 2002, p. 56.

(9) AZEVEDO, 2002, p. 6. 


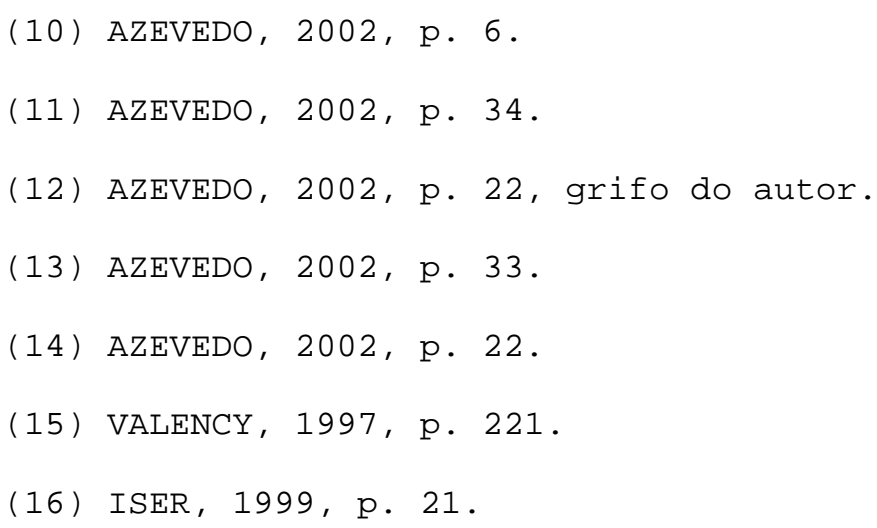

\section{Bibliografia}

AZEVEDO, R. Um homem no sótão. São Paulo: Cia Melhoramentos, 1982.

AZEVEDO, R. Uma velhinha de óculos, chinelos e vestido azul de bolinhas brancas. São Paulo: Companhia das Letrinhas, 1994 .

JAUSS, H. R. A história da literatura como provocação à teoria literária. Tradução Sérgio Tellaroli. São Paulo: Ática, 1994.

ISER, W. O ato da leitura: uma teoria do efeito estético. Tradução Johannes Kretscmer. Vol. 1. São Paulo: Editora 34, 1996.

Teoria da ficção: indagações à obra de Wolfgang Iser. João Cezar de Castro (Org.). Tradução Bluma Waddington et al. Rio de Janeiro: EDUERJ, 1999.

A indeterminação e a resposta do leitor na prosa de fiç̧ão. Tradução Maria Ângela Aguiar. Cadernos do Centro de Pesquisas Literárias da PuCRS. Porto Alegre: Publicação do Curso de Pós-graduação em Letras, volume 3 , Número 2 , março de 1999 .

LIMA, Luiz Costa (Org.). Literatura e o leitor: textos de estética da recepção Hans Robert Jauss et al. Tradução de Luiz Costa Lima. Rio de Janeiro: Paz e Terra, 1979.

REIS, C. LOPES, A. C M. Dicionário de Narratologia. Coimbra: Almedina, 1988 . 